\title{
Microbial Transformation of the Steroidal Alkaloid Dictyophlebine by Rhizopus stolonifer
}

\author{
Krishna Prasad Devkota, ${ }^{*}, a, b$ Muhammad Iqbal Choudhary ${ }^{c}$ Sarfaraz Ahmed Nawaz, ${ }^{c}$ \\ Alain Meli Lannang, ${ }^{c}$ Bruno Ndjakou Lenta, ${ }^{b, d}$ Patrice Aime Fokou, ${ }^{b}$ and Norbert Sewald ${ }^{b}$ \\ ${ }^{a}$ Institute of Forestry, Tribhuvan University; P.O. Box: 43, Pokhara, Kaski, Nepal: ${ }^{b}$ Organic and Bioorganic Chemistry, \\ Department of Chemistry, Bielefeld University; 33501 Bielefeld, Germany: ${ }^{c}$ H.E.J. Research Institute of Chemistry, \\ International Center for Chemical Sciences, University of Karachi; Karachi-75270, Pakistan: and ${ }^{d}$ Department of \\ Chemisty, Higher Teachers' Training College, University of Yaoundé 1; P.O. Box 47, Yaoundé, Cameroon. \\ Received November 29, 2006; accepted January 5, 2007
}

\begin{abstract}
The microbial transformation of a steroidal alkaloid, dictyophlebine (1) with Rhizopus stolonifer (ATCC 10404) afforded three oxidized metabolites $2-4$. Compound 2 was found to be a new product. These metabolites were structurally characterized on the basis of modern spectroscopic techniques. Their inhibitory activity towards acetyl- and butyrylcholinesterase has been evaluated and the new product 2 has been found to be more potent than the parent compound and other metabolites.
\end{abstract}

Key words dictyophlebine; Rhizopus stolonifer; oxidized metabolite; cholinesterase inhibition

Fungal transformation involves the use of different fungi to perform chemical reactions in which the starting substances and products are of comparable chemical complexity. Microbial enzymes are capable of performing a diverse range of reactions including the insertion of oxygen into $\mathrm{C}-\mathrm{H}$ and $\mathrm{C}-\mathrm{C}$ bonds, the addition of oxygen to an alkene, the transfer of acyl or sugar units from one substrate to another; the hydrolysis or formation of amides, epoxides, esters and nitriles, hydrogenation, hydrolysis and elimination of small units, epimerization and isomerization reactions, and formation of $\mathrm{C}-\mathrm{C}, \mathrm{C}-\mathrm{O}, \mathrm{C}-\mathrm{S}$, and $\mathrm{C}-\mathrm{N}$ bonds. These activities have attracted the attention of chemists because enzymes are efficient chiral catalysts and can be used as part of a strategy for enantiospecific syntheses. ${ }^{1)}$ They are characterized by high stereoselectivity, ease of handling, low cost and environmental friendly processes. ${ }^{2)}$ Microbial transformation of progesterone to the important steroidal hormone cortisol opens a new era in this field especially for the transformation of steroidal compounds to therapeutically useful substances. ${ }^{3)}$

In our ongoing study to find potent cholinesterase inhibitors from the plant Sarcococca hookeriana BAILL., we reported a number of compounds displaying this activity. ${ }^{4,5)} \mathrm{We}$ also reported the single crystal X-ray diffraction of dictyophlebine (1), which was the first report of X-ray structure of the $5 \alpha$-pregnane type steroidal alkaloid of this genus. ${ }^{6}$ This paper presents the metabolism of dictyophlebine (1) by Rhizopus stolonifer along with the cholinesterase inhibitory activity of the new product $\mathbf{2}$, which has been obtained for the first time in a microbial transformation.

\section{Results and Discussion}

Dictyophlebine (1) was isolated in a large quantity $(900.0 \mathrm{mg})$ from the alkaline fraction of the dichloromethane extract of $S$. hookeriana. As no biotransformation of this compound was reported in the literature, we subjected this compound to the biotransformation in screening scale experiment, which has shown that the Rhizopus stolonifer (ATCC 10404) is capable of converting compound 1 into three polar metabolites. Preparative scale fermentation was thus carried out to produce sufficient quantities of metabolites for struc- ture elucidation and activity evaluation. One new metabolite $\mathbf{2}$ and two known metabolites $\mathbf{3}$ and $\mathbf{4}$ were obtained after $12 \mathrm{~d}$ of incubation (Chart 1).

Compound 2 was obtained as a colorless solid from the chloroform extract of the culture broth having the molecular formula $\mathrm{C}_{27} \mathrm{H}_{46} \mathrm{~N}_{2} \mathrm{O}_{2}$, as established by HR-EI-MS $(\mathrm{m} / \mathrm{z}$ 430.3550) and ${ }^{13} \mathrm{C}$-NMR data indicating six double bond equivalents. The IR spectrum of compound 2 shows absorptions at $3645(\mathrm{NH}), 1660(\mathrm{C}=\mathrm{O})$ and $1624(\mathrm{C}=\mathrm{C}) \mathrm{cm}^{-1}$. $^{7)}$ The characteristic mass fragmentation pattern of 2 indicates the presence of a pregnane-type steroidal skeleton with two nitrogen substituents at $\mathrm{C}-3$ and $\mathrm{C}-20 .{ }^{8,9)}$ This skeleton was further supported by the comparative ${ }^{1} \mathrm{H}-\mathrm{NMR}$ data of $\mathbf{2}$ with that of parent compound 1. Furthermore, the ${ }^{1} \mathrm{H}-\mathrm{NMR}$ spectrum (Table 1) of compound $\mathbf{2}$ exhibits two overlapping multiplets integrating for two protons resonating at $\delta 4.07-4.14$ that correspond to the diastereotopic $\mathrm{C}-2^{\prime}$ methylene protons. Similarly, further multiplets at $\delta 2.99-3.05$ were assigned to the $\mathrm{C}-3^{\prime}$ methylene protons. A triplet resonating at $\delta 1.21$ $\left(J_{4^{\prime} 3^{\prime}}=7.0 \mathrm{~Hz}\right)$ was due to the propyl $\mathrm{CH}_{3}$ group. A multiplet at $\delta 4.10$ was assigned to $\mathrm{H}-3 \alpha$, whereas a doublet at $\delta 5.39$ $\left(J_{3 \alpha, \mathrm{NH}}=7.4 \mathrm{~Hz}\right)$ was assigned to the urethane $\mathrm{NH}$. A broad singlet at $\delta 5.49$ was due to an olefinic proton and was assigned to $\mathrm{H}-16$. A quartet integrating for one proton at $\delta 2.02$ $\left(J_{20,21}=6.9 \mathrm{~Hz}\right)$ was assigned to the $\mathrm{C}-20$ methine proton, which further supports the unsaturation at C-16/C-17. The unsaturation at C-16 was also supported by EI-MS, in which the peak at $\mathrm{m} / \mathrm{z} 72$ had a lower intensity in comparison with the mass spectra of common steroidal alkaloids with a C-20 $\mathrm{Me}_{2} \mathrm{~N}$ group, in which it is always the base peak. ${ }^{10)}$ The ${ }^{1} \mathrm{H}-{ }^{1} \mathrm{H}$ COSY $45^{\circ}$ spectrum (Fig. 1) displays cross signals between $\mathrm{H}-2 / \mathrm{H}-3 ; \mathrm{H}-3 / \mathrm{H}-4 ; \mathrm{H}-2^{\prime} / \mathrm{H}-3^{\prime}$ and $\mathrm{H}-3^{\prime} / \mathrm{H}-4^{\prime}$. In the ${ }^{13} \mathrm{C}$-NMR spectrum (Table 1), the downfield signal at $\delta 158.6$ supported the presence of a carbamate moiety, whereas other signals at $\delta 151.4$ and 123.2 which were assigned to $\mathrm{C}-17$ and $\mathrm{C}-16$ indicated the presence of a trisubstituted $\mathrm{C}=\mathrm{C}$ bond. In the HMBC spectrum (Fig. 1), H-3/C-2, C-4, C-1'; $\mathrm{H}-16 / \mathrm{C}-17, \mathrm{C}-15, \mathrm{C}-20$ and Me-4'/C-3', C-2' correlations were observed. Hence, these studies on spectroscopic data of compound 2 indicated that it is distinctly similar to that of 


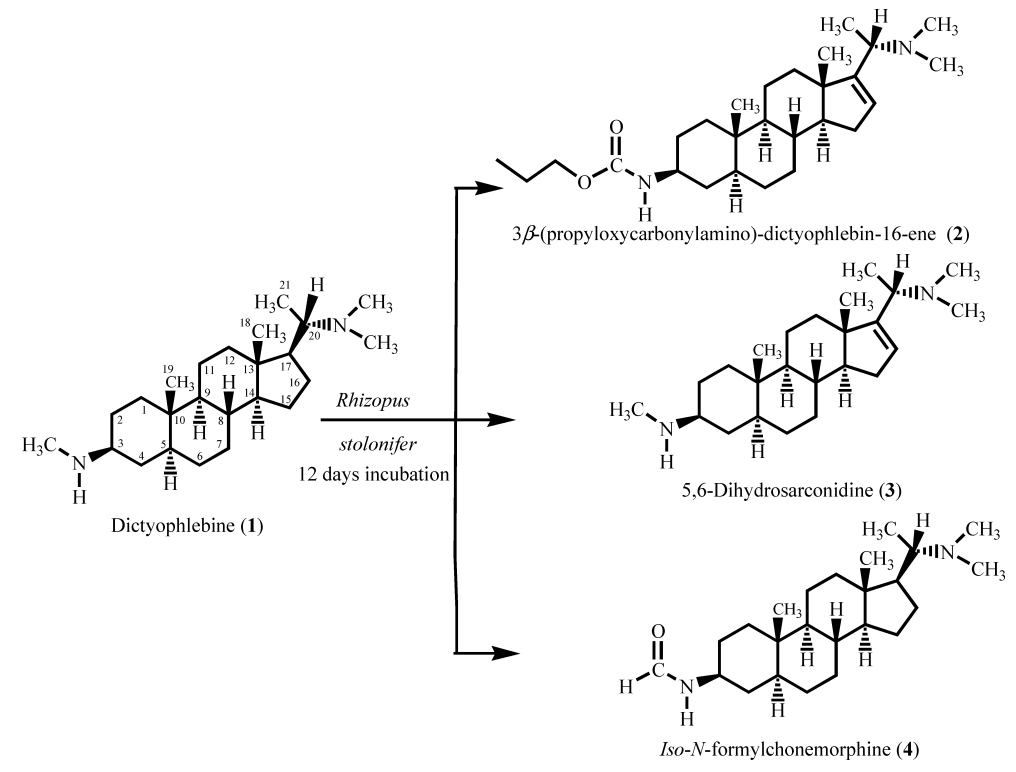

Chart 1. Fungal Transformation of Dictyophlebine (1) by R. stolonifer

Table 1. ${ }^{1} \mathrm{H}-(400 \mathrm{MHz})$ and ${ }^{13} \mathrm{C}-\mathrm{NMR}(100 \mathrm{MHz})$ Data for $3 \beta$-(Propyloxycarbonylamino)-dictyophlebin-16-ene (2) in $\mathrm{CDCl}_{3}$

\begin{tabular}{rlr}
\hline \hline No & \multicolumn{1}{c}{$\delta^{1} \mathrm{H}(J \mathrm{~Hz})$} & $\delta^{13} \mathrm{C}$ \\
\hline 1 & $1.38,1.30, \mathrm{~m}$ & 39.3 \\
2 & $1.61,1.48, \mathrm{~m}$ & 31.0 \\
3 & $4.10, \mathrm{~m}$ & 49.0 \\
4 & $1.44,1.31, \mathrm{~m}$ & 35.3 \\
5 & $1.57, \mathrm{~m}$ & 44.2 \\
6 & $2.41,1.55, \mathrm{~m}$ & 20.6 \\
7 & $1.58,1.48, \mathrm{~m}$ & 31.6 \\
8 & $1.51, \mathrm{~m}$ & 34.2 \\
9 & $0.88, \mathrm{~m}$ & 53.1 \\
10 & - & 35.5 \\
11 & $1.72,1.60, \mathrm{~m}$ & 24.7 \\
12 & $1.56,1.49, \mathrm{~m}$ & 34.1 \\
13 & - & 41.7 \\
14 & $1.77, \mathrm{~m}$ & 55.6 \\
15 & $1.72,1.65, \mathrm{~m}$ & 33.1 \\
16 & $5.49, \mathrm{br} \mathrm{s}$ & 123.2 \\
17 & - & 151.4 \\
18 & $0.81, \mathrm{~s}$ & 12.2 \\
19 & $1.23, \mathrm{~s}$ & 14.6 \\
20 & $2.02, \mathrm{q},(6.4)$ & 14.6 \\
21 & $1.25, \mathrm{~d},(6.9)$ & 14.8 \\
$\mathrm{Me}_{2} \mathrm{~N}$ & $2.12, \mathrm{~s}$ & 39.3 \\
$1^{\prime}$ & - & 158.6 \\
$2^{\prime}$ & $4.07-4.14, \mathrm{~m}$ & 61.0 \\
$3^{\prime}$ & $2.99-3.05, \mathrm{~m}$ & 22.6 \\
$4^{\prime}$ & $1.21, \mathrm{t},(7.0)$ & 12.1 \\
& & \\
\hline
\end{tabular}

All chemical shift assignments were done on the basis of ${ }^{1} \mathrm{H}-{ }^{1} \mathrm{H}$ COSY, HMQC, HMBC and DEPT NMR techniques.

parent compound $\mathbf{1}$, with differences of a propyloxycarbonylamino substituent at $\mathrm{C}-3 \beta$ and one unsaturation at $\mathrm{C}-16 .{ }^{11}$ ) These findings lead to the structure of compound 2 as $3 \beta$ (propyloxycarbonylamino)-dictyophlebin-16-ene [(20S)-20( $N, N$-dimethylamino)-3 $\beta$-(propyloxycarbonylamino)-5 $\alpha$ pregn-16-ene]. The selective hydroxylation at $\mathrm{C}-16$ and its dehydration as well as microbial oxidation of C-3 $N$-methyl by $R$. stolonifer might have afforded compound 2 .

5,6-Dihydrosarconidine (3) and ISO-N-formylchonemorphine (4) were assigned as known compounds by comparison

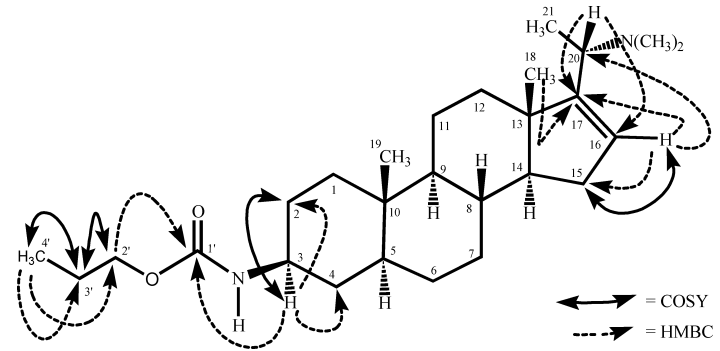

Fig. 1. Key COSY and HMBC Correlations in Compound 2

of their spectroscopic data with the literature values. ${ }^{11,12)}$ The selective hydroxylation at C-16 and its dehydration by $S$. stolonifer might have afforded compound $\mathbf{3}$, whereas, in the case of compound 4, the selective oxidation of C-3 $N$-methyl to the aldehyde might be brought about by $R$. stolonifer .

The acetyl- and butyrylcholinesterase (AChE and BChE) activities of compounds $\mathbf{1}, \mathbf{3}$ and $\mathbf{4}$ have already been reported. ${ }^{13)}$ The $\mathrm{IC}_{50}$ value for compound $\mathbf{2}$ was found to be $2.2 \mu \mathrm{M}$ and $1.2 \mu \mathrm{M}$ for acetyl- and butyrylcholinesterase enzymes, respectively ( $\mathrm{IC}_{50}$ value of standard galanthamine was 0.5 and $8.2 \mu \mathrm{M}$ for $\mathrm{AChE}$ and $\mathrm{BChE}$, respectively). This data show that the new metabolite $\mathbf{2}$ displays more potent cholinesterase inhibitory activity than the parent compound $\mathbf{1}$ $\left(\mathrm{IC}_{50}=6.2\right.$ and $3.6 \mu \mathrm{M}$ for $\mathrm{AChE}$ and $\mathrm{BChE}$, respectively).

\section{Experimental}

General Experimental Procedure Optical rotations were measured on a Jasco digital polarimeter (model DIP-3600) in methanol. UV spectra were recorded in methanol on a Hitachi UV 3200 spectrophotometer. IR spectra were recorded in $\mathrm{CHCl}_{3}$ on a Jasco A-302 IR spectrophotometer. The EI-MS spectra were recorded on a double focusing mass spectrometer (Varian MAT 311A). HR-EI-MS were recorded on Jeol HX 110 mass spectrometer. The ${ }^{1} \mathrm{H}-\mathrm{NMR}$ spectra were recorded on a Bruker AM 400 instrument at $400 \mathrm{MHz}$, while ${ }^{13} \mathrm{C}-\mathrm{NMR}$ spectra were recorded on a Bruker AM 400 operating at $100 \mathrm{MHz}$ using $\mathrm{CDCl}_{3}$ as solvent. Methyl, methylene and methine carbons were distinguished by DEPT $90^{\circ}$ and $135^{\circ}$ experiments. Homonuclear ${ }^{1} \mathrm{H}-{ }^{1} \mathrm{H}$ connectivities were determined by using the COSY $45^{\circ}$ experiment. One-bond ${ }^{1} \mathrm{H}-{ }^{13} \mathrm{C}$ connectivities were determined by HMQC gradient pulse factor selection. Two- and three-bond ${ }^{1} \mathrm{H}-{ }^{13} \mathrm{C}$ connectivities were determined by HMBC experiment. Proton chemical shifts are reported in $\delta$ 
(ppm) relative to the residual $\mathrm{CDCl}_{3}$ signal at $\delta 7.26$, and ${ }^{13} \mathrm{C}-\mathrm{NMR}$ spectra are referenced to the central peak of $\mathrm{CDCl}_{3}$ at $\delta 77.0$. Coupling constants $(J)$ are given in $\mathrm{Hz}$. Column chromatography was carried out on silica gel 60 (70-230 mesh sizes, E. Merck). Precoated silica gel TLC plates (E. Merck, $\mathrm{F}_{254}$ ) were used to check the purity of compounds, and Dragendorff's spray reagent was used for the staining of compounds on TLC.

Acetylcholinesterase, butyrylcholinesterase, acetylthiocholine iodide, butyrylthiocholine chloride, 5,5'-dithiobis[2-nitrobenzoic-acid] (DTNB), and galanthamine were purchased from Sigma (St. Louis, MO, U.S.A.). Buffer and all other chemicals were of analytical grades.

Organism and Media Microbial culture was obtained from American Type Culture Collection (ATCC). Cultures were maintained on Sabouraud Dextrose Agar (SDA) and stored at $4{ }^{\circ} \mathrm{C}$ prior to use. The medium for Rhizopus stolonifer (ATCC 10404) (3.01, distilled $\mathrm{H}_{2} \mathrm{O}$ ) contained glucose $(60.0 \mathrm{~g})$, glycerol $(30.0 \mathrm{~g})$, peptone $(30.0 \mathrm{~g})$, yeast extract $(8.0 \mathrm{~g})$ and $\mathrm{KH}_{2} \mathrm{PO}_{4}(15.0 \mathrm{~g})$; the $\mathrm{pH}$ of the solution was adjusted to 5.6 by adding few drops of $0.04 \mathrm{~N} \mathrm{NaOH}$.

Fermentation of Dictyophlebine (1) with Rhizopus stolonifer The fermentation medium was distributed among 40 flasks of $250 \mathrm{ml}$ capacity ( $100 \mathrm{ml}$ in each) and autoclaved. The fermentation was carried out according to a standard two-stage protocol (Betts et al., 1974). Compound 1 ( $800 \mathrm{mg}$ ) was dissolved in EtOH $(20 \mathrm{ml})$ and equally distributed into 40 flasks $(20 \mathrm{mg} / 0.5 \mathrm{ml}$ in each flask), containing $24 \mathrm{~h}$ old stage II cultures and fermentation was continued for further additional time $(12 \mathrm{~d})$ on a rotary shaker $(200 \mathrm{rpm})$ at $29^{\circ} \mathrm{C}$. During the fermentation period, aliquots from flasks were taken daily and analyzed by TLC in order to determine the degree of substrate transformation. In all experiments, one control flask without $R$. stolonifer (for checking substrate stability) and one flask without substrate (for monitoring endogenous metabolites) were used. The culture media and mycelium were separated by filtration and the filtrate was extracted with $\mathrm{CH}_{2} \mathrm{Cl}_{2}(3 \times 1.51)$. The combined organic extract was washed with brine and dried over anhydrous $\mathrm{Na}_{2} \mathrm{SO}_{4}$, evaporated under reduced pressure to afford a brown gum $(1.5 \mathrm{~g})$. The crude extract was subjected to column chromatography (silica gel). Elution with a gradient of petroleum ether and acetone with a few drops of diethyl amine afforded metabolites 2 (10\% acetone- $90 \%$ petroleum ether with a few drops of $\left.\mathrm{Et}_{2} \mathrm{NH}\right), 3(20 \%$ acetone- $80 \%$ petroleum ether with a few drops of $\left.\mathrm{Et}_{2} \mathrm{NH}\right)$ and $4(5 \%$ acetone- $95 \%$ petroleum ether with a few drops of $\mathrm{Et}_{2} \mathrm{NH}$ ).

$3 \beta$-(Propyloxycarbonylamino)-dictyophlebin-16-ene (2): White amorphous solid (4.4 mg); Rf 0.49 (pet. ether/acetone/Et $2 \mathrm{NH}, 76: 30: 4),[\alpha]_{\mathrm{D}}^{25}$ $+120\left(c=0.3, \mathrm{CHCl}_{3}\right), \mathrm{UV}(\mathrm{MeOH}) \mathrm{nm}(\log \varepsilon): \lambda_{\max } 220(3.1) ; \lambda_{\min } 361$ (3.3), 209 (2.2).; IR $\left(\mathrm{CHCl}_{3}\right) v_{\max } \mathrm{cm}^{-1}: 3645(\mathrm{NH}), 1660(\mathrm{C}=\mathrm{O})$ and 1624 $(\mathrm{C}=\mathrm{C}) ;{ }^{1} \mathrm{H}-\mathrm{NMR}\left(400 \mathrm{MHz}, \mathrm{CDCl}_{3}\right)$ and ${ }^{13} \mathrm{C}-\mathrm{NMR}\left(100 \mathrm{MHz}, \mathrm{CDCl}_{3}\right)$ : see
Table 1; HR-EI-MS $m / z$ : 430.3550 (Calcd for $\mathrm{C}_{27} \mathrm{H}_{46} \mathrm{~N}_{2} \mathrm{O}_{2}$, 430.3559); EIMS $m / z$ (rel. int.): 430 ( $\left.\mathrm{M}^{+}, 8\right), 415$ (100), 72 (22), 43 (4).

In Vitro Cholinesterase Inhibition Assay and Determination of $\mathrm{IC}_{50}$ The procedure that has been described previously was followed. ${ }^{4,5)}$

Acknowledgements We wish to acknowledge Third World Academy of Science (TWAS) for Ph. D. fellowship and to the Alexander von Humboldt $(\mathrm{AvH})$ foundation for post-doctoral fellowship to K. P. Devkota respectively to the HEJ Research Institute of Chemistry, University of Karachi, Pakistan and Bielefeld University, Germany.

\section{References}

1) Quiros M., Rebolledo F., Liz R., Gotor V., Tetrahedron Asymmetry, 8, 3035-3038 (1997).

2) Atta-ur-Rahman, Farooq A., Anjum S., Choudhary M. I., Curr. Org. Chem., 3, 309-326 (1999).

3) Peterson D. H., Murray H. C., Epstein S. H., Reineke L. M., Weintraub A., Meister P. D., Leigh H. M., J. Am. Chem. Soc., 74, 5933-5936 (1952).

4) Choudhary M. I., Devkota K. P, Nawaz S. A., Shaheen F., Atta-ur-Rahman, Helv. Chim. Acta, 87, 1099-1108 (2004).

5) Choudhary M. I., Devkota K. P., Nawaz S. A., Ranjit R., Atta-ur-Rahman, Steroids, 70, 295-303 (2005).

6) Choudhary M. I., Devkota K. P., Anjum S., Rahman A. A., Fun Hoong-Kun, Atta-ur-Rahman, Acta Crystallographica, E59, o1682o1684 (2003)

7) Pavia D. L., Lampman G. M., Kriz G. S., "Introduction to Spectroscopy," 2nd ed., Harcourt Brace College Publishers, U.S.A., 1996.

8) Budzkiewicz H., Djerassi C., Williams D. H., "Structure Elucidation of Natural Products by Mass Spectrometry," Vol. 2, Holden-Day, Inc., San Francisco, 1964, p. 5.

9) Kalauni S. K., Choudhary M. I., Shaheen F., Manandhar M. D., Attaur-Rahman, Gewali M. B., Khalid A., J. Nat. Prod., 64, 842-844 (2001).

10) Zou Z. M., Li L. J., Yang M., Yu S. S., Cong P. Z., Yu D. Q., Phytochemistry, 46, 1091-1093 (1997).

11) Atta-ur-Rahman, Zaheer-ul-Haq, Feroz F., Khalid A., Nawaz S. A., Khan M. R., Choudhary M. I., Helv. Chim. Acta, 87, 439-448 (2004).

12) Atta-ur-Rahman, Anjum S., Farooq A., Khan M. R., Choudhary M. I., Phytochemisty, 46, 771-775 (1997).

13) Khalid A., Zaheer-ul-Haq, Anjum S., Khan M. R., Atta-ur-Rahman, Choudhary M. I., Bioorg. Med. Chem., 12, 1995-2003 (2004). 